\title{
EVALUASI KINERJA EMBUNG SONG BOLONG SELOPAMIORO IMOGIRI, BANTUL
}

\author{
Oleh: Muchamad Arif Budiyanto', Agung Prasetyo² \\ E-mail: arifbudiyanto.sipil@gmail.com
}

\begin{abstract}
ABSTRAK: Small dam is a water storage system, which is usually used by residents in areas with limited water resources. Construction of small dam Song Bolong as one of the water storage is expected to be used to increase agricultural products in the area of small dam Song Bolong.

This study intends to determine the optimization of the use of small dam Song Bolong in order to know the area of land that can be rised by the water availability of small dam Song Bolong. This study uses the software that is in Ms. Excel as a tool in optimization analysis. The optimization Model used is monthly optimization on MT I, MT II and MT III. The goal function is the maximum yield of the small dam Song Bolong to meet the need for irrigation water. While obstacle functions include the magnitude of available discharge, the volume of the reservoir and the available land area. Based on the results of the optimization, the water potential in small dam Song Bolong provides maximum planting intensity with rice planting pattern system (Mt I) - Palawija (Mt II) Palawija (Mt III), at the beginning of January period 1 planting, which shows the planting intensity occurs by $168 \%$ for one year. At MT I The planting intensity is 140\%. At MT II The planting intensity is $20 \%$. As for MT III the planting intensity is $8 \%$.
\end{abstract}

Keywords: irrigation water supplies, optimization, water availability

\section{PENDAHULUAN}

\subsection{Latar Belakang}

Pertanian merupakan profesi yang banyak digeluti oleh masyarakat Daerah Istimewa Yogyakarta. Berdasarkan data yang diperoleh dari Biro Tata Pemerintahan Sekretariat Daerah DIY tahun 2019, jumlah penduduk Provinsi Daerah Istimewa Yogyakarta yang bekerja di bidang Pertanian sebanyak 521.055 jiwa atau sekitar 17,9\%. Tepatnya di daerah Kelurahan Selopamioro Kabupaten Bantul penduduk yang bekerja sebagai petani sebanyak 6.969 jiwa.

Dalam bidang pertanian salah satu faktor penentu keberhasilan dalam memperoleh hasil pertanian yang memuaskan adalah cukupnya ketersediaan air, dalam pergantian bulan di setiap tahun musim selalu berganti adakalanya musim kemarau dan musim penghujan.

Jika pada bulan tertentu berada pada musim penghujan maka para petani tidak perlu khawatir dalam memperoleh air yang cukup bagi kebutuhan tanaman mereka. Tetapi jika bulan itu berada pada musim kemarau atau curah hujan yang turun hanya sedikit maka akan terjadi berkurangnya debit air dari sumber air irigasi sehingga debit air yang tersedia tidak bisa mencukupi kebutuhan air bagi tanaman para petani.

Masalah ini tidak mustahil juga bisa dialami oleh masyarakat petani di Kabupaten Bantul pada umumnya dan masyarakat petani di Kelurahan Selopamioro khususnya, terlebih bagi mereka yang bekerja di sawah yang jenis tanamannya tidak lain adalah padi yang selalu menuntut air yang lebih banyak dibanding tanaman lainnya.

Sebagai salah satu alternatif untuk memecahkan masalah ini, di Kelurahan Selopamioro khususnya di Dusun Lanteng 1 telah di bangun Embung Song Bolong untuk memenuhi kebutuhan air irigasi.

1 adalah Staf Pengajar pada Jurusan Teknik Sipil Fakultas Teknik Universitas Cokroaminoto Yogyakarta.

2 adalah Mahasiswa Jurusan Teknik Sipil Fakultas Teknik Universitas Cokroaminoto Yogyakarta. 


\subsection{Rumusan Masalah}

Embung Song Bolong ini sebagai sumber air untuk irigasi area pesawahan khususnya di Dusun Lanteng 1 dan Dusun Lanteng 2. Tetapi ketika memasuki musim kemarau Embung Song Bolong ini tidak bisa mencukupi kebutuhan air untuk area pesawahan.

\subsection{Batasan Masalah}

Batasan-batasan masalah pada penelitian ini adalah :

a. Berdasarkan latar belakang masalah yang ditulis di atas, maka permasalahan penelitian pada bangunan Embung Song Bolong ini yang akan dilakukan di batasi mencakup hal-hal sebagai berikut, yaitu untuk memperoleh detail Embung, Analisa data curah hujan, Analisa kebutuhan air irigasi (khususnya tanaman padi).

b. Embung ini juga dipergunakan sebagai pengganti tadah hujan untuk menampung air sebanyaknya sesuai kebutuhan untuk areal pesawahan di lokasi Embung tersebut.

\subsection{Tujuan dan Manfaat Penelitian}

Adapun tujuan dari penelitian ini adalah sebagai berikut :

a. Untuk mendapatkan berapa besar kapasitas volume tampungan air pada Embung Song Bolong.

b. Menghitung luasan sawah yang bisa di cukupi kebutuhan air dari Embung Song Bolong.

Sebagai manfaat, Tugas Akhir ini di harapkan dapat memberikan solusi dalam memenuhi kekurangan kebutuhan air irigasi bagi masyarakat Dusun Lanteng 1 dan Lanteng 2.

\section{LANDASAN TEORI}

\subsection{Siklus Hidrologi}

Secara umum pengertian Hidrologi adalah cabang ilmu geografi yang mempelajari seputar pergerakan, distribusi, dan kualitas air yang ada di bumi.

Siklus Hidrologi scara umum adalah sirkulasi air dari laut ke atmosfer lalu ke bumi dan kembali lagi ke laut dan seterusnya

\subsection{Definisi Embung}

Embung adalah bangunan konservasi air berbentuk kolam untuk menampung air hujan dan air limpasan serta sumber air lainya untuk mendukung usaha pertanian, perkebunan dan pertenakan terutama pada saat musim kemarau. Embung merupakan cekungan yang dalam di suatu daerah perbukitan (Yudi Apandi, 2019).

\subsubsection{Analisa Volume Embung}

Fungsi utama embung adalah untuk memanfaatkan air pada musim penghujan, menampung air sehingga dapat di manfaatkan pada musim kemarau. Hal yang terpenting dari embung adalah kapasitas embung atau kapasitas tampungan yang meliputi :

a. Kapasitas Efektif adalah volume tampungan dari embung yang dapat dimanfaatkan untuk melayani kebutuhan air yang ada.

b. Kapasitas mati adalah volume tampungan untuk sedimen. Kapasitas tampungan tersebut perlu di ketahui sebab merupakan dasar untuk perencanaan bangunanbangunan seperti bendungan, spillway, maupun intake. 


\subsubsection{Analisa Penyedia Air}

Lengkung Kapasitas Embung.

Lengkung kapasitas embung merupakan grafik yang menghubungkan luas daerah genangan dengan volume tampungan terhadap elevasinya. Berhubung fungsi utama embung adalah untuk menyediakan tampungan, maka ciri fisik utama yang terpenting adalah kapasitas tampungan.

\subsection{Daerah Aliran Sungai}

Daerah Aliran Sungai (DAS) adalah daerah yang di batasi punggung-punggung gunung dimana air hujan yang jatuh pada daerah tersebut akan di tampung oleh punggung gunung tersebut dan akan dilarikan melalui sungai-sungai kecil ke sungai utama (Asdak, 1995).

\subsection{Debit Andalan}

Debit andalan (dependable flow) adalah debit yang selalu tersedia sepanjang tahun yang dapat dipakai untuk irigasi. Dalam penelitian ini debit andalan merupakan debit yang memiliki probabilitas $80 \%$. Debit dengan probabilitas $80 \%$ adalah debit yang memiliki kemungkinan terjadi di bendung sebesar $80 \%$ dari $100 \%$ kejadian.

\subsection{Evapotranspirasi}

Evapotranspirasi atau disebut penguapan adalah gabungan dari dua peristiwa yakni evaporasi dan transpirasi yang terjadi secara bersamaan disebut juga peristiwa evapotranspirasi. Kedua proses ini sulit untuk dibedakan karena keduanya terjadi secara simultan.Banyak rumus tersedia untuk menghitung besarnya evapotranspirasi yang terjadi, salah satunya adalah Metode Penman.

\subsubsection{Perhitungan Evapotranspirasi Metode Penman}

Metode ini pertama kali dibuat oleh H.L Penman (Rothamsted Experimental Station, Harpenden, England) tahun 1984. Metode Penman pada mulanya dikembangkan untuk menentukan besarnya evaporasi dari permukaan air terbuka (ETO). Banyak rumus tersedia untuk menghitung besarnya evapotranspirasi yang terjadi salah satunya adalah Metode Penman.

\subsubsection{Faktor-faktor Klimatologi}

Faktor-faktor yang mempengaruhi besarnya evapotranspirasi adalah sebagai berikut: 1. Radiasi Matahari

Evapotransirasi merupakan konversi air ke dalam uap air. Proses ini berjalan terus hampir tanpa berhenti di siang hari dan kerap kali juga di malam hari.

\section{Angin}

Jika air menguap ke atmosfir maka batas lapisan atas antara permukaan tanah dan udara menjadi jenuh oleh uap air sehingga proses penguapan berhenti.

3. Kelembaban Udara

Faktor lain yang mempengaruhi evapotranspirasi adalah kelembaban relative udara.

4. Suhu (Temperatur).

Jika suhu udara dan tanah cukup tinggi, proses evapotranspirasi berjalan lebih cepat dibandingkan dengan jika suhu udara dan tanah rendah dengan adanya energi panas yang tersedia.

5. Variasi Elevasi / Ketinggian.

Pada suatu zona iklim tertentu ET akan berbeda sesuai dengan ketinggian dihitung dari elevasi permukaan air laut. 


\subsection{Analisa Kebutuhan Air Untuk Irigasi}

\subsubsection{Curah Hujan Efektif}

Turunnya curah hujan pada suatu areal lahan mempengaruhi pertumbuhan tanaman di areal tersebut. Curah hujan tersebut dapat dimanfaatkan oleh tanaman untuk mengganti kehilangan air yang terjadi akibat evapotranspirasi, perkolasi, kebutuhan pengolahan tanah dan penyiapan lahan.

\subsubsection{Kebutuhan Air di Sawah.}

Kebutuhan air untuk tanaman pada suatu jaringan irigasi merupakan air yang dibutuhkan untuk tanaman untuk pertumbuhan yang optimal tanpa kekurangan air yang dinyatakan dalam Netto Kebutuhan Air Lapang ( Net Field Requirement, NFR ).

\subsubsection{Kebutuhan Penyiapan Lahan.}

Pada Standar Perencanaan irigasi disebutkan bahwa kebutuhan air untuk penyiapan lahan umumnya menentukan kebutuhan maksimum air irigasi pada suatu proyek irigasi. Ada 2 faktor penting yang menentukan besarnya kebutuhan air untuk penyiapan lahan ialah:

a. Lamanya waktu yang di butuhkan untuk penyiapan lahan.

b. Jumlah air yang di perlukan untuk penyiapan lahan.

Metode yang dapat digunakan untuk perhitungan kebutuhan air irigasi selama penyiapan lahan salah satunya adalah metode yang dikembangkan oleh van de Goor dan Zijlstra (1968).

\subsubsection{Klimatologi.}

Klimatologi juga disebut penguapan adalah gabungan dari dua peristiwa yakni evaporasi dan transpirasi yang terjadi secara bersamaan disebut juga peristiwa evapotranspirasi.

\subsubsection{Evaporasi.}

Mengingatkan evaporasi dipengaruhi oleh berbagai-bagai faktor, maka adalah sulit untuk menghitung evaporasi dengan suatu rumus. Akan tetapi.

\section{METODE PENELITIAN}

\subsection{Umum.}

Metode penelitian merupakan cara untuk memperoleh hasil dari penelitian secara keseluruhan guna memperoleh data yang dibutuhkan dan akan digunakan selanjutnya untuk dianalisa sehingga memperoleh kesimpulan yang ingin dicapai dalam penelitian. Langkah-langkah dalam metode penelitian adalah:

\section{A. Diskripsi lokasi penelitian.}

Lokasi penelitian ini berada di Dusun Lanteng 1, Selopamioro, Imogiri, Bantul.

\section{B. Pengumpulan Data}

Dalam pengumpulan data ini ada 2 jenis data yaitu data primer dan data skunder.

\section{Pengolahan dan Analisis Data.}

Dalam penelitian ini menganalisis data : curah hujan, kebutuhan air irigasi, kapasitas Embung, dan keseimbangan air.

D. Waktu Penelitian.

Waktu pelaksanaan penelitian akan di laksanakan dalam waktu bulan terhitung dari bulan april hingga bulan juli 2020. 


\section{E. Rincian Penelitian.}

Secara garis besar tahapan - tahapan yang di tempuh dalam melaksanakan penelitian ada 3 tahap, yaitu : tahap perencanaan, pelaksanaan penelitian, laporan penelitian

\section{PEMBAHASAN DAN HASIL PENELITIAN}

\subsection{Diskripsi Lokasi Penelitian}

Desa Selopamioro termasuk wilayah Kecamatan Imogiri Kabupaten Bantul, Kecamatan Imogiri terdiri dari 14 (empat belas) Desa. Sedangkan Desa Selopamioro terletak disisi Barat daya Ibu Kota Kecamatan dengan batas wilayah:

1. Sebelah Utara : Desa Girirejo dan Desa Mangunan

2. Sebelah Timur : Desa Mangunan dan Desa Girisubo

3. Sebelah Selatan : Desa Giriharjo dan Desa Girisubo

4. Sebelah Barat : Desa Sariharjo

\subsection{Hasil Dan Pembahasan}

\subsubsection{Pola Tanam di Daerah Layanan Embung Song Bolong}

Pola tanam merupakan usaha penanaman pada sebidang lahan dengan mengatur susunan tata letak dan urutan tanaman selama periode waktu tertentu termasuk masa pengolahan tanah dan masa tidak ditanami selama periode tertentu. Pola tanam daerah layanan Embung Song Bolong mempunyai pola tanam pada bulan Oktober Penyiapan lahan dan pada 1 tahun Padi, Padi, Palawija.

\subsubsection{Data Kebutuhan air}

Analisis ketersediaan air ditentukan oleh kandungan air tanah dan curah hujan efektif. Menurut Direktorat Jendral pengairan (1986) kontribusi air tanah sangat dipengaruhi oleh karakteristrik tanah, di daerah irigasi Song Bolong untuk karekteristik tanahanya sendiri yaitu clay.

Pada jenis tanah lempung (clay) laju perkolasi 1-2 mm/ hr. Pada tanah yang lebih ringan laju perkolasi bisa lebih tinggi.

\subsubsection{Curah Hujan Efektif}

Curah hujan efektif ditentukan besarnya R80 yang merupakan curah hujan yang besarnya dapat dilampaui sebanyak $80 \%$ atau dengan kata lain dilampauinya 8 kali kejadian dari 10 kali kejadian. Dengan kata lain bahwa besarnya curah hujan yang lebih kecil dari R80 mempunyai kemungkinan hanya $20 \%$.

\subsubsection{Evapotranspirasi}

Evapotranspirasi (ETo) adalah proses dimana air berpindah dari permukaan bumi ke atmosfer termasuk evaporasi air dari tanah dan transpirasi dari tanaman melalui jaringan tanaman melalui transfer panas laten persatuan area (Hilel, 1983).

\subsubsection{Kebutuhan Air Persiapan Lahan}

Kebutuhan air irigasi adalah jumlah volume air yang diperlukan untuk memenuhi kebutuhan evaporasi, kehilangan air, kebutuhan air untuk tanaman dengan memperhatikan jumlah air yang diberikan oleh alam melalui hujan dan kontribusi air tanah (Anonim,1996). Kebutuhan Air Irigasi yang diambil untuk Daerah Irigasi Embung Song Bolong adalah periode harian tengah bulanan.

Dilihat dari tabel perhitungan kebutuhan air persiapan lahan dapat disimpulkan bahwa untuk nilai $\operatorname{IR}(250)$ terbesar berada pada bulan Oktober priode 1 dan 2 dengan nilai 8,30 $\mathrm{mm} /$ hari dan nilai IR terkecil berada di bulan November priode 1 dan 2 dengan nilai 5,07 $\mathrm{mm} /$ hari. 


\subsubsection{Kebutuhan Air Untuk Tanaman}

Kebutuhan air tanaman di definisikan sebagai jumlah air yang dibutuhkan oleh tanaman pada satu periode untuk dapat tumbuh dan berproduksi secara normal. Kebutuhan air nyata untuk areal usaha pertanian meliputi evapotranspirasi (ET), sejumlah air yang dibutuhkan untuk pengoperasian secara khusus seperti penyiaapan lahan dan penggantian air.

Dilihat dari data tabel perhitungan kebutuhan air tanaman maka nilai NFR terbesar berada pada bulan Oktober priode 2 dengan nilai 1,703 It/dt dan dengan nilai NFR terkecil bada pada bulan Januari priode 1 dengan nilai $0,473 \mathrm{lt} / \mathrm{dt}$. Dan dilihat dari data di atas untuk pola tanam masyarakat di daerah layanan Embung Song Bolong menggunakan : Padi ( MT I ) - Padi ( MT II ) - Palawija ( MT III ).

\subsubsection{Analisa Kebutuhan Air di Intake}

Dalam analisa kebutuhan air di intake ini menggunakan nilai asumsi efesiensi 0,85 $(85 \%)$ untuk saluran primer dan sekunder. Dan untuk luas area pelayanan dalam analisa ini menggunakan luas 25,78 ha pada MT I-MT II-MT III.

Dari hasil perhitungan neraca air diatas dengan pola tanam: Padi ( MT I ) - Padi ( MT II ) - Palawija ( MT III ) dapat diketahui kebutuhan air di Embung Song Bolong yaitu paling tinggi berada pada bulan Oktober priode 2 dengan nilai $0,061 \mathrm{~m}^{3} / \mathrm{dt}$, sedangkan nilai terkecil berada pada bulan Januari priode 1 dengan nilai $0,017 \mathrm{~m}^{3} / \mathrm{dt}$.

\subsubsection{Ketersediaan Air}

Analisis hidrologi dilakukan dengan analisis statistik, karena data tersedia terdapat data debit harian, sehingga langsung di cari debit rata -rata. Debir rata-rata inflow ke Embung Song Bolong didapat dari hasil analisis perbandingan (rasio luas DAS) data debit di stasiun AWLR Kedung Miri. Diketahui dari data teknis luas cacthment DAS Embung Song Bolong adalah $2 \mathrm{~km}^{2}$. Maka dapat dihitung debit yang mengalir.

Dari hasil data debit dapat ditarik kesimpulan bahwa debit inflow terbesar berada di bulan Februari priode 1 dengan $0,120 \mathrm{~m}^{3} /$ det, sedangkan nilai debit inflow terkecil berada di bulan Agustus priode 2 dan September priode 1 dengan 0,002 $\mathrm{m}^{3} / \mathrm{det}$.

\subsubsection{Simulasi Tampungan Embung Song Bolong}

Simulasi ini digunakan untuk mengetahui apakah embung/waduk bisa mencukupi kebutuhan irigasi di area layanannya.

Diketahui elevasi dasar Embung Song Bolong berada pada $\pm 42,00 \mathrm{mdpl}$.

elevasi Intake berada pada \pm 43,00 .m.a.I. dan elevasi pelimpah berada pada $\pm 44,00$ mdpl.

\subsubsection{Simulasi Eksisting}

Berdasarkan persamaan model simulasi diatas maka dapat dilakukan perhitungan simulasi tampungan Embung Song Bolong pada kondisi eksisting

Dari hasil simulasi dengan luas area layanan 25,78 ha pada MT I, MT II, MT III, dan awal tanam pada bulan Oktober priode 2 dapat diketahui bahwa ketersediaan air di Embung Song Bolong tidak bisa untuk memenuhi kebutuhan irigasi di area layananya, dapat di lihat dari kontrol faktor K dengan keberhasilan 11 (46\%) dan kegagalan 13 (54\%).

\subsubsection{Simulasi Optimasi}

Untuk mengetahui pelayanan optimal Embung Song Bolong maka di gunakan perhitungan simulasi optimasi.

Dari hasil simulasi dapat disimpulkan dengan luas area layanan 36,09 ha pada MT I, 5,16 ha pada MT II, 2,06 ha pada MT III, dan awal tanam pada bulan Januari priode 1, hasil faktor $\mathrm{K}$ untuk nilai keberhasilan $100(100 \%)$, dan untuk nilai kegagalan yaitu $0(0 \%)$. 


\section{KESIMPULAN DAN SARAN}

\subsection{Kesimpulan}

Berdasarkan uraian - uraian yang terdapat di dalam BAB IV, penulis dapat menarik kesimpulan bahwa jumlah ketersediaan air di Embung Song Bolong belum cukup untuk memenuhi kebutuhan irigasi dengan luas area layanan 25,78 ha pada MT I, MT II, MT III, dapat dilihat dari hasil simulasi dengan nilai kontrol faktor K keberhasilan 11 (46\%) dan kegagalan $13(54 \%)$.

Dalam hal ini masyarakat di daerah irigasi Embung Song Bolong untuk pola tanam sendiri terdapat padi dan palawija, kemudian untuk padi sendiri untuk kebutuhan air paling tertinggi terdapat di bulan Oktober periode ke 2 dengan nilai 1,703 lt/dt, kemudian untuk palawija paling tertinggi penggunaan airnya di bulan Juli periode ke1 dan 2 dengan nilai $1,354 \mathrm{lt} / \mathrm{dt}$.

\subsection{Saran}

Sehubungan dengan hal ini maka penulis memberikan saran kepada pemerintah Kabupaten Bantul karena ketersediaan air kurang untuk memenuhi kebutuhannya maka untuk mengadakan optimalisasi dengan membagi distribusi air irigasi dengan luas area layanan 36,09 ha pada MT I, 5,16 ha pada MT II, 2,06 ha pada MT III, dan awal tanam pada bulan Januari priode 1 .

\section{DAFTAR PUSTAKA}

Arif Budiyanto, M., 2010. Kajian Pengaruh Pengembangan Pemanfaatan Air Irigasi dan Air Domestik Terhadap Alokasi Air di DAS Opak. Yogyakarka: UGM

Arif Budiyanto, M.,Tornado, 2020. Kajian Kapasitas Saluran Daerah Irigasi Baing Di Kabupaten Sumba Timur Provinsi Nusa Tenggara Timur. Jurnal Teknik Sipil Vol. XV No.1, Yogyakarka

Bardan, Mochammad, 2016, Pengembangan Sumberdaya Air, bahan kuliah Program Studi Teknik Sipil Universitas Cokroaminoto Yogyakarta, Yogyakarta.

Yudi Apandi., 2019. Embung.Diunduh http://cybex.pertanian.go.id/mobile/artikel/77499/EMBUNG/

Rustam, R. K. (2010). Tata Ruang Air. Yogyakarta.

Asdak, C. 1995. Hidrologi dan Pengelolaan Daerah Aliran Sungai. Yogyakarta

KP - 01, 2010. Standar Perencanaan Irigasi, Kriteria Perencanaan Bagian Jaringan Irigasi. Direktorat Jenderal Sumber Daya Air.

Mas Mi. 2016. Penjelasan Terlengkap Tentang Pengertian dan Proses Siklus Air (Hidrologi). Diunduh https://www.pelajaran.co.id/2016/31/pengertian-dan-prosessiklus air-hidrologi.html

Badan Pusat Statistik Kabupaten Bantul, 2019, STATISTIK DAERAH KABUPATEN BANTUL 2019, Badan Pusat Statistik Kabupaten Bantul, Bantul 